\title{
Case Report \\ Euglycemic Diabetic Ketoacidosis in a Patient with Cocaine Intoxication
}

\author{
Asma Abu-Abed Abdin, ${ }^{1}$ Muhammad Hamza, ${ }^{2}$ Muhammad S. Khan, ${ }^{3}$ and Awab Ahmed ${ }^{3}$ \\ ${ }^{1}$ Jordan University for Science and Technology, P.O. Box 3030, Irbid 22110, Jordan \\ ${ }^{2}$ Department of Medicine, Dow Medical College, Baba-E-Urdu Road, Karachi 74200, Pakistan \\ ${ }^{3}$ Section of Pulmonary \& Critical Care Medicine, University of Oklahoma Health Sciences Center, 920 Stanton L Young Boulevard, \\ Oklahoma City, OK 73104, USA
}

Correspondence should be addressed to Muhammad S. Khan; muhammad-khan@ouhsc.edu

Received 13 June 2016; Revised 11 July 2016; Accepted 12 July 2016

Academic Editor: Moritoki Egi

Copyright (C) 2016 Asma Abu-Abed Abdin et al. This is an open access article distributed under the Creative Commons Attribution License, which permits unrestricted use, distribution, and reproduction in any medium, provided the original work is properly cited.

\begin{abstract}
Diabetic ketoacidosis (DKA) is characterized by elevated anion gap metabolic acidosis, hyperglycemia, and elevated ketones in urine and blood. Hyperglycemia is a key component of DKA; however, a subset of DKA patients can present with near-normal blood glucose, an entity described as "euglycemic DKA." This rare phenomenon is thought to be due to starvation and food restriction in insulin dependent diabetic patients. Cocaine abuse is considered a trigger for development of DKA. Cocaine also has anorexic effects. We describe an interesting case of euglycemic DKA in a middle-aged diabetic female presenting with elevated anion gap metabolic acidosis, with near-normal blood glucose, in the settings of noncompliance to insulin and cocaine abuse. We have postulated that cocaine abuse was implicated in the pathophysiology of euglycemic DKA in this case. This case highlights complex physiological interplay between type-1 diabetes, noncompliance to insulin, and cocaine abuse leading to DKA, with starvation physiology causing development of euglycemic DKA.
\end{abstract}

\section{Introduction}

The hallmark of diabetic ketoacidosis (DKA) is hyperglycemia, metabolic acidosis, and increased ketones [1]. The absence of hyperglycemia, defined as serum glucose concentration greater than $250 \mathrm{mg} / \mathrm{dL}$ [1], makes the diagnosis of DKA less obvious in a patient with elevated serum anion gap metabolic acidosis and positive serum and urine ketones. However, euglycemic DKA has been well described in the literature mainly in type-1 diabetic patients, starvation, gestational diabetes, and more recently the settings SGLT inhibitor use. We describe a case of middle-aged women, who presented with severe metabolic acidosis, ketonemia, and near-normal blood glucose in the settings of noncompliance to insulin and cocaine use leading to poor oral intake. This case report also reviews possible physiologic interplay between lack of insulin and cocaine use leading to DKA.

\section{Case}

A fifty-seven-year-old female presented to emergency room with altered mental status, nausea, vomiting, and abdominal pain. The patient was in usual state of health 2 days before presentation, when she developed intermittent dull epigastric pain. The patient was able to tolerate the pain initially, but on day of presentation the pain became severe and persistent and she started having nonbilious vomiting. She also became somnolent and tachypneic and therefore the decision was made to bring her to the emergency room. Her past medical history was significant for diabetes mellitus and she was on insulin monotherapy. The family reported that for the last few weeks the patient was noncompliant with using insulin. On initial evaluation her vital signs were remarkable for temperature of 37 degree Celsius, pulse of $120 /$ minutes, blood pressure (BP) of $134 / 78 \mathrm{mmHg}$, respiratory rate of 24 breath/minute, and oxygen saturation of 
95\% on 2-liter nasal cannula. Pertinent examination findings included obtunded patient who did not wake up to deep sternal rub, dry oral mucosa, and a weak gag reflex. Her pulmonary and cardiovascular examination was unremarkable. Admission labs indicated severe uncompensated metabolic acidosis with arterial blood gas showing $\mathrm{pH}$ of $7.02, \mathrm{PaCO}_{2}$ of $14, \mathrm{PaO}_{2}$ of 134 , calculated bicarbonate of 4 , and oxygen saturation of $97 \%$. Serum chemistries indicated sodium $137 \mathrm{mEq} / \mathrm{L}(136-145 \mathrm{mEq} / \mathrm{L})$, potassium $4.4 \mathrm{mEq} / \mathrm{L}$ (3.5-5.1 mEq/L), chloride $82 \mathrm{mEq} / \mathrm{L}$ (97-109 mEq/L), bicarbonate $<10 \mathrm{mEq} / \mathrm{L}(23-32 \mathrm{mEq} / \mathrm{L})$, blood urea nitrogen (BUN) $32 \mathrm{mg} / \mathrm{dL}$ (7-17 mg/dL), serum creatinine $2.84 \mathrm{mg} / \mathrm{dL}$ (0.7-1.1 mg/dL), serum glucose $172 \mathrm{mg} / \mathrm{dL}(66-111 \mathrm{mg} / \mathrm{dL})$, measured serum anion gap 46 (4-14), and measured serum osmolality $324 \mathrm{mOsm} / \mathrm{kg}$ (280-300 mOsm/kg). Her urine analysis was positive for ketones. Urine and serum drug screen was positive for cocaine. Other labs including complete blood count, lactic acid, serum Tylenol levels, and liver function tests were within normal limits. Admission chest roentgenogram was unremarkable (Figure 1).

Given concern for severe uncompensated metabolic acidosis and decreased sensorium, the patient was intubated for airway protection. Initial differential diagnosis included toxic alcohol ingestion, euglycemic diabetic ketoacidosis, alcoholic ketoacidosis, and starvation ketoacidosis. The serum ethanol, methanol, ethylene glycol, and propylene glycol were undetectable on admission labs and serum betahydroxybutyrate (BHB) levels were significantly elevated $15.95 \mathrm{mmol} / \mathrm{L}(0.02-0.27 \mathrm{mmol} / \mathrm{L})$ confirming the diagnosis of euglycemic diabetic ketoacidosis. As the patient's blood glucose was $172 \mathrm{mg} / \mathrm{dL}$ on admission, we initially administered 1 liter bolus of intravenous (IV) 5\% Dextrose and $0.45 \%$ normal saline (D5-1/2 NS), followed by a maintenance rate of $250 \mathrm{cc} /$ hour, supplemented with $20 \mathrm{mEq}$ of potassium chloride IV per liter of D5-1/2 NS. Insulin drip was initiated at a rate of 0.1 units/kg/hour. Finger stick blood glucose was checked hourly to maintain blood glucose between 150 and $200 \mathrm{mg} / \mathrm{dL}$. Basic metabolic panel and BHB levels were checked at four-hour interval. After initial 4 liters of volume resuscitation, the patient's anion gap started to close and in 18 hours period her gap closed completely as shown in Table 1.

The patient was subsequently transitioned to subcutaneous insulin. Her mentation improved and she was extubated. After extubation patient confirmed that she was on a cocaine binge for 2 days and missed her insulin doses during that time. The patient was transferred out of medical intensive care unit and was discharged from hospital subsequently.

\section{Discussion}

Diabetic ketoacidosis (DKA) is defined by the American Diabetes Association as having a combination of hyperglycemia (glucose > $250 \mathrm{mg} / \mathrm{dL}$ ), acidosis (arterial $\mathrm{pH}<$ 7.3 and bicarbonate $<15 \mathrm{mEq} / \mathrm{L}$ ), and ketosis (moderate ketonuria or ketonemia) [1]. Normally, human bodies have balance between insulin levels and their counter regulatory hormones which include glucagon, epinephrine, cortisol, and growth hormone. Any factor that causes decrease in insulin

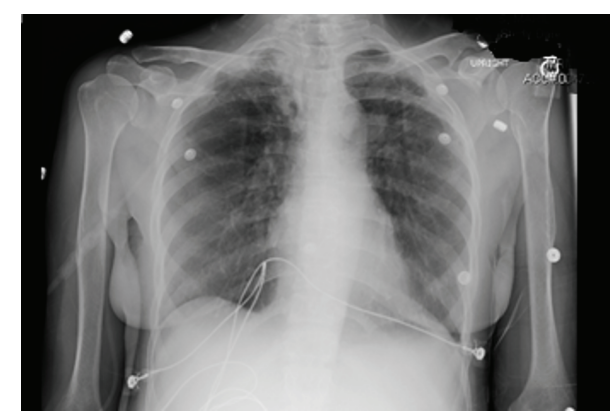

Figure 1: Chest X-ray on admission.

levels or increase in its counter regulatory hormones or both will lead to development of DKA [1].

Rare cases of DKA have been found to occur in the absence of true hyperglycemia; such cases are called euglycemic DKA. This phenomenon was first reported by Munro et al., when 37 out of 211 studied DKA cases were found to be normoglycemic (defined as a serum glucose level of $300 \mathrm{mg} / \mathrm{dL}(16.7 \mathrm{mmol} / \mathrm{L})$ or lower and a plasma bicarbonate level of $10 \mathrm{mmol} / \mathrm{L}$ or lower at presentation) [2]. Thereafter, these criteria have been adjusted to consider serum glucose level of $200 \mathrm{mg} / \mathrm{dL}$ as a threshold for the diagnosis of euglycemic DKA. The underlying mechanism of this rare entity is either decreased hepatic production of glucose during fasting states or enhanced urinary excretion of glucose induced by increase in counter regulatory hormones, with the former being the more important; that is, when a diabetic patient is exposed to any triggering factor for DKA and is fasting for any cause while continuing his insulin treatment regularly, the liver will be in a state of glycogen depletion, which in turn leads to decreased hepatic glucose production and increased lipolysis and fatty acid production, and this finally will lead to decreased glucose production while ketone bodies formation is continuous, ending in a state of euglycemic DKA [3]. Some of the causes that have been reported to induce euglycemic DKA include low caloric intake and starvation or prolonged vomiting, pregnancy, pancreatitis, insulin pump use, and SGLT2 inhibitors [4-9]. Table 2 gives major differentiating points between hyperglycemia DKA and euglycemic DKA.

Euglycemic DKA can be distinguished from other forms of ketoacidosis including starvation ketoacidosis, and alcoholic ketoacidosis, by clinical history and serum bicarbonate levels. The serum bicarbonate concentration in starvation ketoacidosis is usually more than $18 \mathrm{mEq} / \mathrm{L}$ [10]. The absence of other causes of elevated anion gap metabolic acidosis such as lactic acidosis, elevated toxic serum alcohols (methanol, ethylene glycol, etc.), drug toxicity, paraldehyde ingestion, and renal failure can distinguish DKA.

In the current case, the patient presented with severe uncompensated metabolic acidosis, ketonuria, and ketonemia in the absence of true hyperglycemia. After excluding other possibilities of wide anion gap metabolic acidosis including ethanol, methanol, or ethylene glycol ingestion, the diagnosis of euglycemic DKA was made and it was treated accordingly by IV 5\% Dextrose, $0.45 \%$ normal saline, and 
TABLE 1: Basic metabolic panel, beta-hydroxybutyrate, and serum $\mathrm{pH}$ from time of admission to closure of anion gap.

\begin{tabular}{lcccccc}
\hline & Admission & Six hours apart & Four hours apart & Four hours apart & Four hours apart & Four hours apart \\
\hline Sodium & $137 \mathrm{mEq} / \mathrm{L}$ & $139 \mathrm{mEq} / \mathrm{L}$ & $139 \mathrm{mEq} / \mathrm{L}$ & $138 \mathrm{mEq} / \mathrm{L}$ & $138 \mathrm{mEq} / \mathrm{L}$ & $137 \mathrm{mEq} / \mathrm{L}$ \\
Potassium & $4.4 \mathrm{mEq} / \mathrm{L}$ & $4.8 \mathrm{mEq} / \mathrm{L}$ & $4.3 \mathrm{mEq} / \mathrm{L}$ & $4.1 \mathrm{mEq} / \mathrm{L}$ & $3.9 \mathrm{mEq} / \mathrm{L}$ & $4.2 \mathrm{mEq} / \mathrm{L}$ \\
Chloride & $82 \mathrm{mEq} / \mathrm{L}$ & $102 \mathrm{mEq} / \mathrm{L}$ & $103 \mathrm{mEq} / \mathrm{L}$ & $105 \mathrm{mEq} / \mathrm{L}$ & $107 \mathrm{mEq} / \mathrm{L}$ & $107 \mathrm{mEq} / \mathrm{L}$ \\
Bicarbonate & $<10 \mathrm{mEq} / \mathrm{L}$ & $<10 \mathrm{mEq} / \mathrm{L}$ & $10 \mathrm{mEq} / \mathrm{L}$ & $15 \mathrm{mEq} / \mathrm{L}$ & $21 \mathrm{mEq} / \mathrm{L}$ & $22 \mathrm{mEq} / \mathrm{L}$ \\
Blood urea nitrogen & $32 \mathrm{mg} / \mathrm{dL}$ & $25 \mathrm{mg} / \mathrm{dL}$ & $22 \mathrm{mg} / \mathrm{dL}$ & $19 \mathrm{mg} / \mathrm{dL}$ & $15 \mathrm{mg} / \mathrm{dL}$ & $14 \mathrm{mg} / \mathrm{dL}$ \\
Creatinine & $2.84 \mathrm{mg} / \mathrm{dL}$ & $1.82 \mathrm{mg} / \mathrm{dL}$ & $1.69 \mathrm{mg} / \mathrm{dL}$ & $1.66 \mathrm{mg} / \mathrm{dL}$ & $1.20 \mathrm{mg} / \mathrm{dL}$ & $1.06 \mathrm{mg} / \mathrm{dL}$ \\
Glucose & $172 \mathrm{mg} / \mathrm{dL}$ & $251 \mathrm{mg} / \mathrm{dL}$ & $180 \mathrm{mg} / \mathrm{dL}$ & $198 \mathrm{mg} / \mathrm{dL}$ & $166 \mathrm{mg} / \mathrm{dL}$ & $95 \mathrm{mg} / \mathrm{dL}$ \\
Anion gap & 46 & 28 & 26 & 18 & 10 & 8 \\
B-Hydroxybutyrate & - & $15.95 \mathrm{mmol} / \mathrm{L}$ & - & $4.51 \mathrm{mmol} / \mathrm{L}$ & - & 7.36 \\
pH & 7.02 & 7.13 & 7.26 & & 7.34 & \\
\hline
\end{tabular}

TABLE 2: Major differences between hyperglycemic DKA and euglycemic DKA.

\begin{tabular}{ll}
\hline Hyperglycemic DKA & Euglycemic DKA \\
\hline Blood glucose $>250 \mathrm{mg} / \mathrm{dL}$, arterial $\mathrm{pH}<7.3$, and & Blood glucose $<200 \mathrm{mg} / \mathrm{dL}$, arterial $\mathrm{pH}<7.3$, and serum bicarbonate $<$ \\
serum bicarbonate $<18 \mathrm{mEq} / \mathrm{L}$ & $18 \mathrm{mEq} / \mathrm{L}$ \\
$\begin{array}{l}\text { Insulin deficiency and increased counter regulatory } \\
\text { hormones causing hyperglycemia }\end{array}$ & Insulin deficiency and increased counter regulatory hormones causing \\
hyperglycemia and starvation from any cause euglycemia \\
Triggered by infections, concurrent illnesses, and & As a result of decreased circulating glucose in starvation, cirrhosis, exogenous \\
dehydration & insulin use, SGLT-2 inhibitors, pancreatitis, depression, and so forth \\
\hline
\end{tabular}

insulin drip. The patient was screened positive for cocaine in serum and urine drug screen, and thereafter she admitted that she had been on binge cocaine intake for two days before presentation. Interestingly, cocaine has been reported to be a trigger for DKA in many diabetic patients. This is attributed to cocaine's stimulatory effect on cortisol, epinephrine, and norepinephrine release from the adrenal gland $[11,12]$. This increase in counter regulatory hormones is the underlying cause for having DKA with hyperglycemia in such patients.

In this patient, two counter regulatory factors played a role culminating in development of euglycemic DKA. We hypothesize that, with history of noncompliance to insulin and while being on cocaine binge, the patient developed hyperglycemic DKA for two reasons: firstly, from lack of exogenous insulin and secondly from hyperglycemic effect of cocaine via adrenocortical hormones as described above. Conversely, as cocaine has been shown to cause anorexic effect via suppression of feeding centers in central nervous system $[13,14]$ and while being on cocaine binge, the patient developed poor oral intake. This starvation effect led to drop in her blood sugar to normal range. Interestingly, the anorexic, thus, hypoglycemic effects of cocaine were more pronounced in our patient, hence overshadowing the initial hyperglycemia resulting in euglycemic DKA.

In conclusion, euglycemic DKA should be included in differential diagnosis in patients presenting with elevated anion gap metabolic acidosis and near-normal blood glucose, especially in the setting of cocaine abuse. Volume resuscitation and insulin drip initiation remain the cornerstone of treatment and early diagnosis through high index of suspicion is paramount in order to start the right treatment.

\section{Competing Interests}

The authors declare that they have no competing interests.

\section{References}

[1] E. A. Nyenwe and A. E. Kitabchi, "The evolution of diabetic ketoacidosis: an update of its etiology, pathogenesis and management," Metabolism, vol. 65, no. 4, pp. 507-521, 2016.

[2] J. F. Munro, I. W. Campbell, A. C. McCuish, and L. J. Duncan, "Euglycaemic diabetic ketoacidosis," British Medical Journal, vol. 2, no. 5866, pp. 578-580, 1973.

[3] M. S. Rauf, "Euglycemic ketoacidosis," Pakistan Journal of Medical Sciences, vol. 24, no. 1, pp. 161-162, 2008.

[4] F. Joseph, L. Anderson, N. Goenka, and J. Vora, "Starvationinduced true diabetic euglycemic ketoacidosis in severe depression," Journal of General Internal Medicine, vol. 24, no. 1, pp.129131, 2009.

[5] A. Gelaye, A. Haidar, C. Kassab, S. Kazmi, and P. Sinha, "Severe Ketoacidosis Associated with Canagliflozin (Invokana): a safety concern," Case Reports in Critical Care, vol. 2016, Article ID 1656182, 3 pages, 2016.

[6] M. Chico, S. N. Levine, and D. F. Lewis, "Normoglycemic diabetic ketoacidosis in pregnancy," Journal of Perinatology, vol. 28, no. 4, pp. 310-312, 2008.

[7] J. Rosenstock and E. Ferrannini, "Euglycemic diabetic ketoacidosis: a predictable, detectable, and preventable safety concern with SGLT2 inhibitors," Diabetes Care, vol. 38, no. 9, pp. 16381642, 2015.

[8] J. Prater and J. Chaiban, "Euglycemic diabetic ketoacidosis with acute pancreatitis in a patient not known to have diabetes," Endocrine Practice, vol. 1, no. 2, pp. e88-e91, 2015. 
[9] E. A. Warner, G. S. Greene, M. S. Buchsbaum, D. S. Cooper, and B. E. Robinson, "Diabetic ketoacidosis associated with cocaine use," Archives of Internal Medicine, vol. 158, no. 16, pp. 1799$1802,1998$.

[10] A. E. Kitabchi, G. E. Umpierrez, J. M. Miles, and J. N. Fisher, "Hyperglycemic crises in adult patients with diabetes," Diabetes Care, vol. 32, no. 7, pp. 1335-1343, 2009.

[11] E. A. Nyenwe, R. S. Loganathan, S. Blum et al., "Active use of cocaine: an independent risk factor for recurrent diabetic ketoacidosis in a city hospital," Endocrine Practice, vol. 13, no. 1, pp. 22-29, 2007.

[12] A. S. Kashyap, K. P. Anand, and S. Kashyap, "Cocaine use a risk factor for DKA," Endocrine Abstracts, vol. 7, abstract P249, 2004.

[13] D. C. Balopole, C. D. Hansult, and D. Dorph, "Effect of cocaine on food intake in rats," Psychopharmacology, vol. 64, no. 1, pp. 121-122, 1979.

[14] S. J. Cooper and G. A. van der Hoek, "Cocaine: a microstructural analysis of its effects on feeding and associated behaviour in the rat," Brain Research, vol. 608, no. 1, pp. 45-51, 1993. 


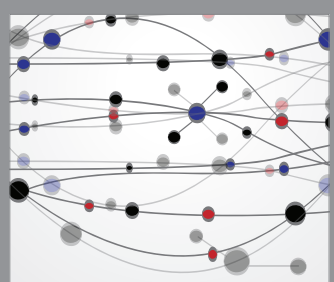

The Scientific World Journal
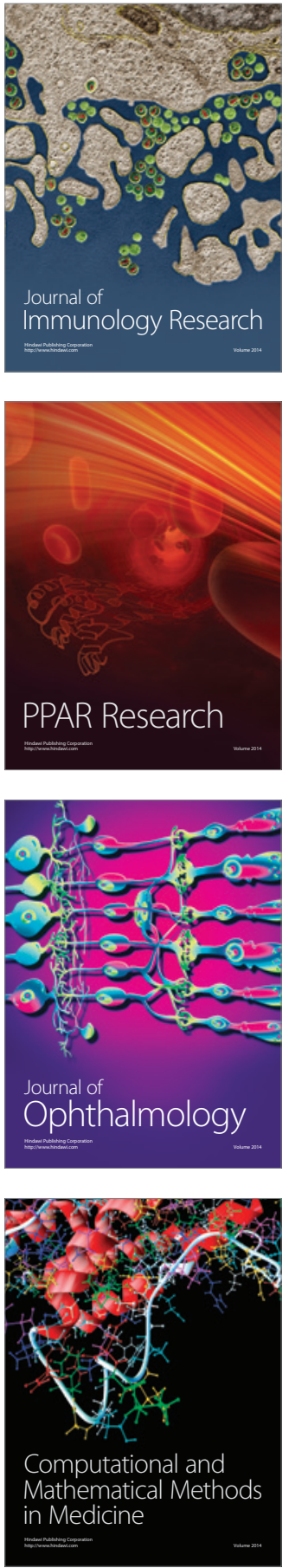

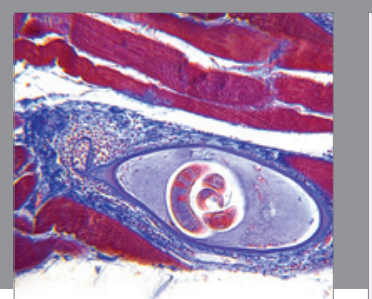

Gastroenterology Research and Practice

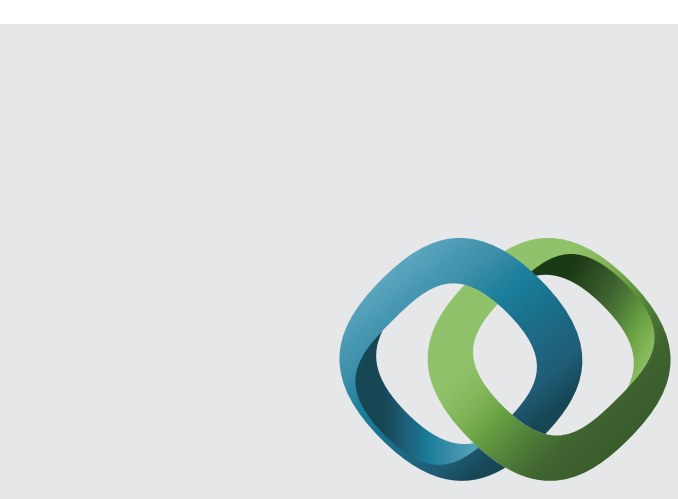

\section{Hindawi}

Submit your manuscripts at

http://www.hindawi.com
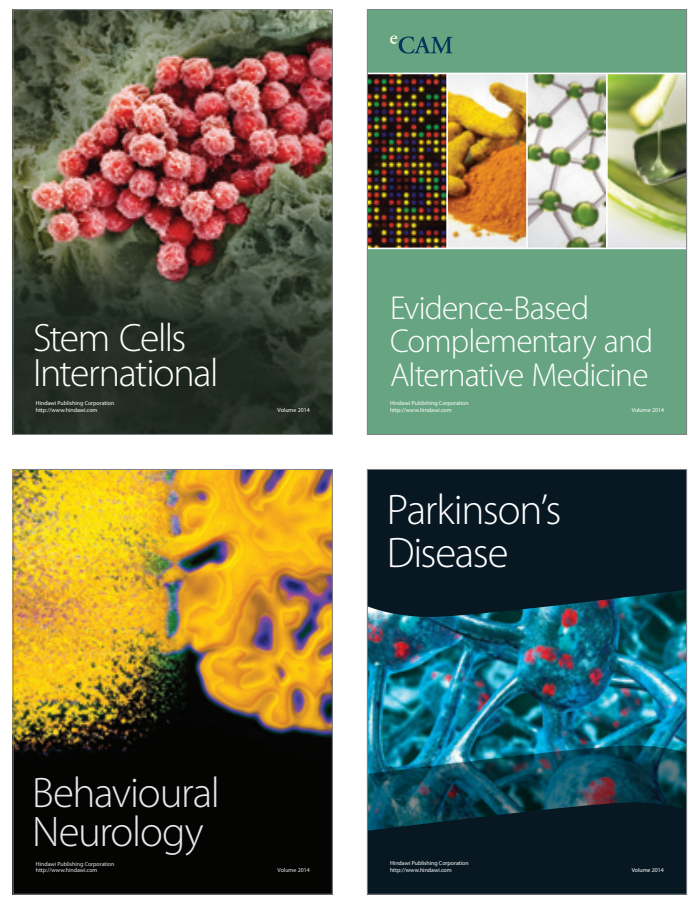
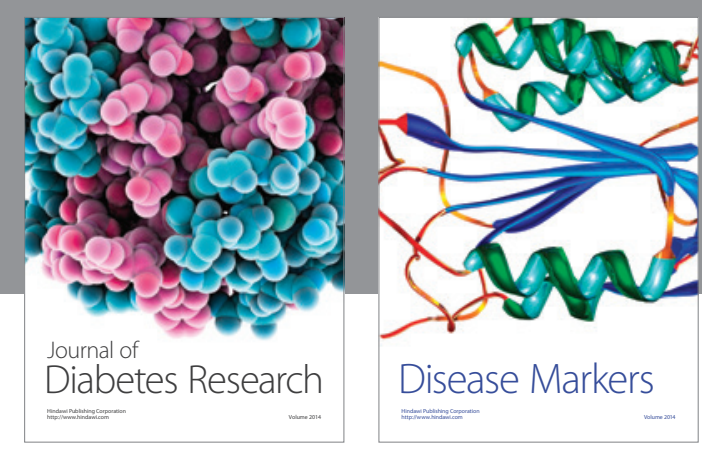

Disease Markers
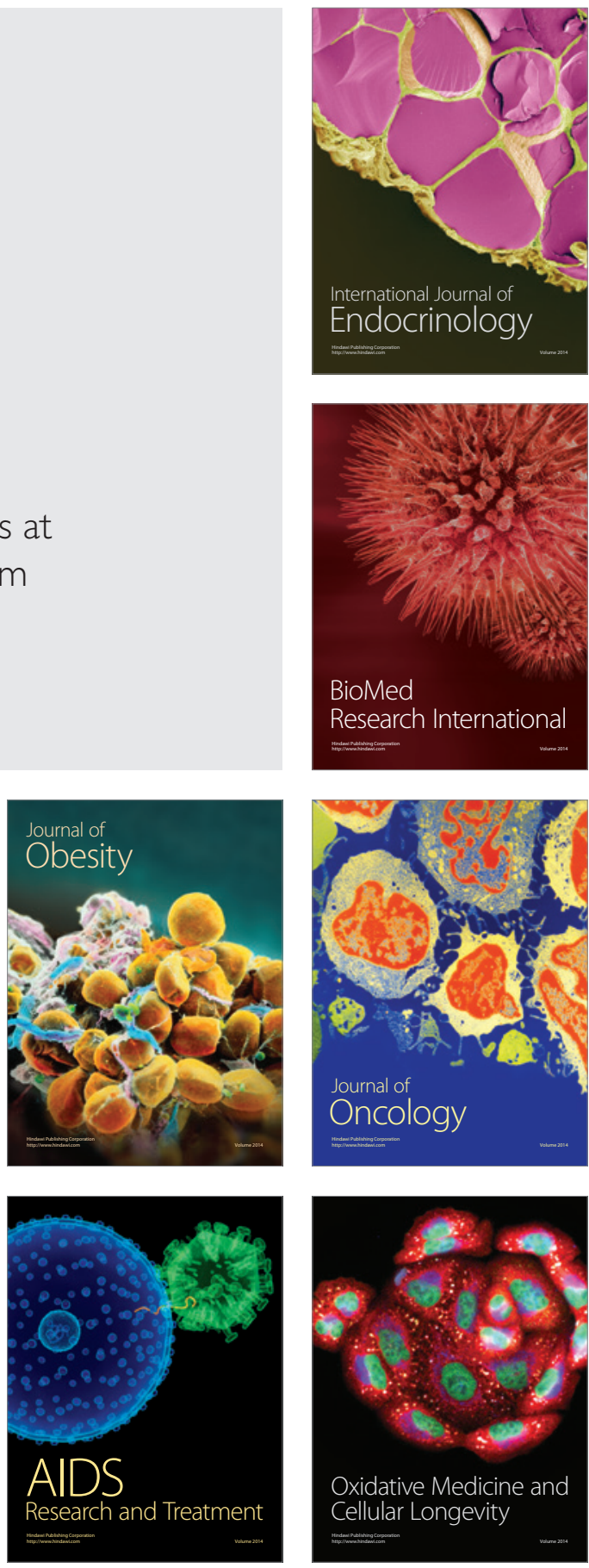